\title{
Near-IR Dye Sensitization of Polymer Blend Solar Cells
}

Huajun Xu, ${ }^{\dagger}$ Hideo Ohkita, ${ }^{\dagger}, * *$, Toshiaki Hirata,${ }^{\dagger}$ Hiroaki Benten, ${ }^{\dagger}$ Shinzaburo Ito $^{\dagger}$

$\dagger$ Department of Polymer Chemistry, Graduate School of Engineering, Kyoto University,

Katsura, Nishikyo, Kyoto 615-8510, Japan

¥Japan Science and Technology Agency (JST), PRESTO, 4-1-8 Honcho Kawaguchi,

Saitama 332-0012, Japan

* Phone: +81-75-383-2613, FAX: +81-75-383-2617, E-mail:

ohkita@photo.polym.kyoto-u.ac.jp

KEYWORDS: Near-IR dye, Dye sensitization, Heterojunction, Naphthalocyanine,

Polymer blend, Solar cell 
ABSTRACT: We have fabricated ternary blend solar cells based on

poly(3-hexylthiophene) (P3HT) as a donor material,

poly $\left\{\left[N, N^{\prime}\right.\right.$-bis(2-octyldodecyl)-naphthalene-1,4,5,8-bis(dicarboximide)-2,6-diyl]-alt-5,

5'-(2,2'-bithiophene)\} (N2200) as an acceptor material, and a silicon naphthalocyanine

derivative $(\mathrm{SiNc})$ as a near-IR sensitizer. In order to discuss how molecular structures

impact the dye sensitization in P3HT/N2200 solar cells, we studied two SiNc molecules

with different axial groups: SiNc10 with decyldimethylsilyl oxide and SiNc6 with

trihexylsilyl oxide. As a result, P3HT/N2200/SiNc10 ternary solar cells exhibited a

power conversion efficiency of $1.4 \%$, which is improved by $73 \%$ compared to

P3HT/N2200 binary solar cells and also by $17 \%$ compared to P3HT/N2200/SiNc6

ternary solar cells. We discuss the origin of the improvement in the device

performance in terms of dye location in ternary blend films. 


\section{Introduction}

Polymer solar cells have made remarkable progress over the last decade. Very recently, a power conversion efficiency (PCE) exceeding 10\% has been reported by several groups.[1,2] This is mainly because various low-bandgap polymers have been developed to harvest the solar light in the near-IR region where a photon flux reach a maximum.[3-8] This approach, however, has a trade-off issue that low-bandgap polymers have an absorption band at a longer wavelength but an absorption window at a shorter wavelength. In other words, it is generally difficult to harvest the solar light over the wide wavelength range from visible to near-IR region only by two donor/acceptor materials of conjugated polymer and fullerene. This is partly due to the limited absorption bandwidth of most conjugated polymers and partly due to small absorption of fullerene derivatives. Thus, it is essentially required for further improvement toward $15 \%$ to harvest much more photons in the solar light over the wide wavelength range from visible to near-IR region.

In order to extend the light-harvesting range from visible to near-IR region, several alternative approaches have been proposed in recent years. Polymer/polymer blend solar cells have potential advantage over the conventional polymer/fullerene solar cells, because both donor/acceptor conjugated polymers have more intense absorption 
bands than that of fullerene derivatives. Thus, it would be possible to collect the solar light over a wide wavelength range by using donor and acceptor conjugated polymers that have complementary absorption bands in the visible and near-IR region. On the other hand, ternary blend solar cells have been proposed as another approach to extending the absorption range from visible to near-IR region in a simple way.[9-22] Previously, we demonstrated that ternary blend solar cells incorporating dye molecules can improve not only the light-harvesting efficiency by additional dye absorption but also the exciton-harvesting efficiency by long-range Förster energy transfer. The key to success is selective dye loading into the donor/acceptor interface where excitons can be dissociated into electron-hole pairs.[13] Both approaches are simple and versatile, and therefore can be easily applied to various material combinations.

In this study, we have integrated these two approaches of polymer/polymer blend solar cells and ternary blend solar cells to extend the light-harvesting range in a simple way. In other words, we addressed dye sensitization of polymer/polymer solar cells. Here, we employed poly(3-hexylthiophene) (P3HT) as a donor material, poly $\left\{\left[N, N^{\prime}\right.\right.$-bis(2-octyldodecyl)-naphthalene-1,4,5,8-bis(dicarboximide)-2,6-diyl]-alt-5, 5'-(2,2'-bithiophene) $\}$ (N2200) as an acceptor material, and two different silicon naphthalocyanine derivatives as a near-IR sensitizer. In order to discuss how 
molecular structures impact the dye sensitization in polymer/polymer blend solar cells, we studied two silicon naphthalocyanine derivatives with different axial groups: silicon naphthalocyanine bis(tri- $n$-hexylsilyl oxide) (SiNc6) and silicon naphthalocyanine bis(n-decyldimethylsilyl oxide) (SiNc10).

\section{Experimental}

Materials. Silicon naphthalocyanine bis(tri-n-hexylsilyl oxide) (SiNc6; Aldrich) was employed without further purification. Silicon naphthalocyanine bis(n-decyldimethylsilyl oxide) (SiNc10) was synthesized as follows. A mixture of silicon naphthalocyanine dihydroxide $\mathrm{SiNc}(\mathrm{OH})_{2}(100 \mathrm{mg})$, n-decyldimethyl chlorosilane $(142 \mu \mathrm{L})$, and dry pyridine $(10 \mathrm{~mL})$ was refluxed for $6 \mathrm{~h}$. After the solution obtained had been allowed to cool, the solvent was evaporated and chloroform was added to the residue. The solution was washed with saturated $\mathrm{NaCl}$ solution, and then dried over $\mathrm{MgSO}_{4}$. After the evaporation of the solvent, the residue was purified by silica gel column chromatography (toluene/hexane $=1 / 1(\mathrm{v} / \mathrm{v})$ as eluent) to afford $\mathrm{SiNc}\left[\mathrm{OSi}\left(\mathrm{CH}_{3}\right)_{2}\left(n-\mathrm{C}_{10} \mathrm{H}_{21}\right)\right]_{2}(78 \mathrm{mg})$ as a green solid (yield $\left.=51 \%\right)$.

UV-visible (toluene): $\lambda_{\max }=773 \mathrm{~nm}\left(\varepsilon=5.8 \times 10^{5} \mathrm{M}^{-1} \mathrm{~cm}^{-1}\right)$

${ }^{1} \mathrm{H}$ NMR (400 MHz, CDC13): $\delta=10.06$ (s, 5,36-Nc, 8H), 8.59 (m, 1,4-Nc, 8H), 7.85(m, 1,4-Nc, 8H), 1.20 (m, 9- $\left.\mathrm{CH}_{2}, 4 \mathrm{H}\right), 1.05\left(\mathrm{~m}, 8-\mathrm{CH}_{2}, 4 \mathrm{H}\right), 0.95$ (m, 7-CH2, 4H), 0.85 (t, 
10- $\left.\mathrm{CH}_{3}, 6 \mathrm{H}\right), 0.65\left(\mathrm{~m}, 6-\mathrm{CH}_{2}, 4 \mathrm{H}\right), 0.50\left(\mathrm{~m}, 5-\mathrm{CH}_{2}, 4 \mathrm{H}\right), 0.15\left(\mathrm{~m}, 4-\mathrm{CH}_{2}, 4 \mathrm{H}\right),-0.15(\mathrm{~m}$,

$\left.3-\mathrm{CH}_{2}, 4 \mathrm{H}\right),-1.10\left(\mathrm{~m}, 2-\mathrm{CH}_{2}, 4 \mathrm{H}\right),-1.95\left(\mathrm{~m}, 1-\mathrm{CH}_{2}, 4 \mathrm{H}\right),-2.60\left(\mathrm{~s}, \mathrm{SiCH}_{3}, 12 \mathrm{H}\right)$.

Sample fabrication. The quartz, glass, or ITO-coated substrates were cleaned by ultrasonication in toluene, acetone, and ethanol each for 15 min, dried with $\mathrm{N}_{2}$, and cleaned with a $\mathrm{UV}-\mathrm{O}_{3}$ cleaner for $30 \mathrm{~min}$. For photoluminescence (PL) quenching measurements, sample films were spincoated on the cleaned quartz substrate. For photovoltaic measurements, poly (3,4-ethylenedioxythiophene):poly(4-styrenesulfonate) (PEDOT:PSS; H.C. Starck PH500) was spincoated onto the cleaned ITO substrate at $3000 \mathrm{rpm}$ and baked at $140{ }^{\circ} \mathrm{C}$ for $10 \mathrm{~min}$ in air. Subsequently, a ternary blend film was spincoated from a $p$-xylene solution of poly(3-hexylthiophene) (P3HT; Plextronics Plexcore OS2100), poly $\{[N, N$ '-bis(2-octyldodecyl)-naphthalene-1,4,5,8-bis(dicarboximide)-2,6-diyl]-alt-5, 5'-(2,2'-bithiophene)\} (N2200; Polyera), and SiNc dyes (SiNc6 or SiNc10) onto the PEDOT:PSS coated ITO substrate. The thickness of each layer was $\sim 40 \mathrm{~nm}$ (PEDOT:PSS) and $\sim 110 \mathrm{~nm}$ (the ternary blend active layer). The ternary blend film was annealed at $140{ }^{\circ} \mathrm{C}$ for $10 \mathrm{~min}$ in an $\mathrm{N}_{2}$-filled glove box. Finally, a metal electrode of $\mathrm{Ca} / \mathrm{Al}$ layer $(15 / 80 \mathrm{~nm})$ was deposited on top of the active layer in sequence at $2.5 \times$ $10^{-4} \mathrm{~Pa}$. The effective device area was $0.07 \mathrm{~cm}^{2}$. 
Measurements. The ionization potential of P3HT, N2200, SiNc6, and SiNc10 was measured with a photoelectron yield spectrometer (Riken Keiki, AC-3). All the neat films (ca. $60 \mathrm{~nm}$ ) were fabricated by spin-coating from a chlorobenzene solution on PEDOT:PSS-coated ITO substrates. The threshold energy for the photoelectron emission was estimated on the basis of the cubic root of the photoelectron yield plotted against the incident photon energy (see the Supplementary Material) as reported previously. $[23,24]$

Absorption and PL spectra of the neat and blend films were measured at room temperature with a spectrophotometer (Hitachi UV-3500) and a fluorescence spectrophotometer (Hitachi F-4500), respectively.

Current density-voltage $(J-V)$ characteristics were measured with a DC voltage and current source/monitor (Advantest R6243) in the dark and under AM1.5G simulated solar illumination at $100 \mathrm{~mW} \mathrm{~cm}$. The light intensity was corrected with a calibrated silicon photodiode reference cell (Bunkoh-Keiki BS-520). The external quantum efficiency (EQE) spectra were measured with a digital electrometer (Advantest R8252) under monochromatic light illumination from a $500 \mathrm{~W}$ xenon lamp (Thermo Oriel Model 66921) with optical cut filters and a monochromator (Thermo Oriel Cornerstone). The illumination was carried out from the ITO side in an $\mathrm{N}_{2}$ atmosphere at room 
temperature. At least 10 devices were measured to ensure the reproducibility of the device performance. 


\section{Results and Discussion}

$-----<<<\quad$ Figure $1 \quad>>>-----$

The HOMO level was evaluated by the photoelectron yield spectroscopy measurements of P3HT, N2200, SiNc6 and SiNc10 neat films. From the threshold energy in the cubic root of the photoelectron yield plotted against the incident photon energy (see the Supplementary Material), the ionization energy was estimated to be 4.7 eV (P3HT), $5.9 \mathrm{eV}$ (N2200), $5.5 \mathrm{eV}$ (SiNc6) and $5.5 \mathrm{eV}$ (SiNc10). The LUMO level was evaluated from the optical bandgap and the HOMO level. From the absorption spectrum and the photoluminescence (PL) spectra of P3HT, SiNc6, SiNc10 and N2200 neat films (see the Supplementary Material), the optical bandgap was estimated to be 2 $\mathrm{eV}(\mathrm{P} 3 \mathrm{HT}), 1.6 \mathrm{eV}(\mathrm{N} 2200), 1.5 \mathrm{eV}(\mathrm{SiNc} 6)$ and $1.5 \mathrm{eV}(\mathrm{SiNc} 10)$. Therefore, the LUMO level was evaluated to be $2.7 \mathrm{eV}$ (P3HT), $4.3 \mathrm{eV}$ (N2200), $4.0 \mathrm{eV}$ (SiNc6) and $4.0 \mathrm{eV}(\mathrm{SiNc} 10)$. As shown in Figure 1, ternary blends of P3HT, N2200, and SiNc dyes exhibit cascaded energy structures both in the HOMO and LUMO levels when dye molecules are located at the donor/acceptor interface of P3HT and N2200. The offset energy is more than $0.3 \mathrm{eV}$ both in HOMO-HOMO and LUMO-LUMO gap, which 
would be large enough for efficient charge generation at the interface. This energetic condition is an absolute requirement for efficient dye sensitization in a longer wavelength region. Indeed, we reported dye sensitization in P3HT/N2200/SiNc6 ternary solar cells previously.[22] As shown in the figure, SiNc10 has the same optoelectronic properties as SiNc6 and therefore equivalent potential for dye sensitization of P3HT/N2200 blend solar cells if blend morphology is the same as well.

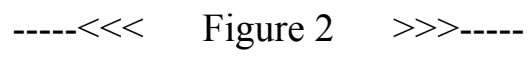

Figures $2 \mathrm{a}$ and $2 \mathrm{~b}$ show $J-V$ characteristics of ternary blend solar cells incorporating SiNc6 or SiNc10 with various dye loading concentrations. As shown in the figure, P3HT/N2200/SiNc6 solar cells exhibit modest improvements in the photocurrent at limited dye concentrations while P3HT/N2200/SiNc10 solar cells exhibit efficient improvements over the all dye loading concentrations up to $50 \mathrm{wt} \%$. The device parameters are summarized in Table 1. This difference is, as shown in Figures $2 \mathrm{c}$ and $2 \mathrm{~d}$, mainly ascribed to the difference in the photocurrent generation efficiency at the dye absorption band. However, as shown in Figures $2 \mathrm{e}$ and $2 \mathrm{f}$, there is no substantial difference in the photon absorption efficiency between them. This 
suggests that SiNc6 and SiNc10 are differently distributed in P3HT/N2200/dye ternary

blend films.

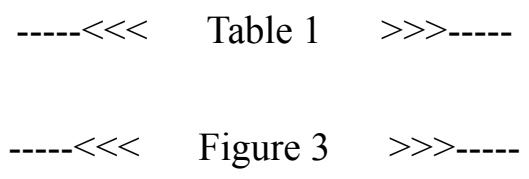

In order to address the origin of the different photocurrent generation in details, we evaluated the contribution of P3HT, N2200, and SiNc dyes to the photocurrent generation from the integration of the product of the EQE and the solar spectrum from 360 to $650 \mathrm{~nm}$ for P3HT, from 650 to $750 \mathrm{~nm}$ for N2200, and from 750 to $850 \mathrm{~nm}$ for SiNc dye. For SiNc6, as shown in Figure 3, the integrated photocurrent due to P3HT and dye bands showed a maximum at $15 \mathrm{wt} \%$ and then decreased at $>15 \mathrm{wt} \%$ while the integrated photocurrent due to N2200 remained constant at $\sim 1 \mathrm{~mA} \mathrm{~cm}^{-2}$. For SiNc10, on the other hand, all the integrated photocurrent monotonically increased up to $50 \mathrm{wt} \%$. In summary, SiNc6 does not contribute to the photocurrent generation at high dye loading concentrations $>15 \mathrm{wt} \%$ while SiNc10 does contribute even at high dye loading concentrations up to $50 \mathrm{wt} \%$. These findings suggest that the dye distribution in ternary blends should be different. 
$-----<<<\quad$ Figure $4 \quad>>>-----$

To discuss the dye location in P3HT/N2200/SiNc, we measured the absorption peak wavelength of dyes in the ternary blend film, which is dependent upon the local concentration of dye molecules as reported previously.[12] For comparison, we also measured that in binary blends of P3HT/SiNc and N2200/SiNc (see the Supplementary Material). For SiNc6, as shown in Figure 4a, the peak wavelength showed a similar trend for all the ternary and binary blend films. It was $772 \mathrm{~nm}$ at $5 \mathrm{wt} \%$, which is the same as that in solution, suggesting that SiNc6 molecules are isolated in polymer matrices at a low dye loading. Thereafter, it steeply jumped to $795 \mathrm{~nm}$ at $\sim 20 \mathrm{wt} \%$ and then approached to $800 \mathrm{~nm}$, which is the same as that of SiNc6 neat films. This steep increase suggests that SiNc6 molecules are likely to be segregated from either P3HT or N2200 domains. For SiNc10, on the other hand, the peak wavelength showed a similar trend for P3HT/SiNc10 and P3HT/N2200/SiNc10 but different for N2200/SiNc10, as shown in Figure 4b. This suggests that SiNc10 molecules are primarily located at P3HT domains in P3HT/N2200/SiNc10 ternary blend films. Similarly to SiNc6, the peak wavelength was $775 \mathrm{~nm}$ at the lowest concentration and 
finally approached to $818 \mathrm{~nm}$ with increasing dye loading concentrations. In contrast to SiNc6, the peak wavelength was gradually shifted from 775 to $818 \mathrm{~nm}$, suggesting that SiNc10 is not likely to be segregated but rather well mixed with P3HT. This difference is consistent with the efficient device performance of P3HT/N2200/SiNc10 with high dye loading concentrations.

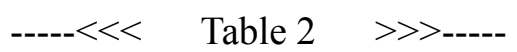

To further understand the dye distribution in terms of materials properties, we measured the surface energy of each material. As summarized in Table 2, the order of the surface energy is as follows: $\mathrm{P} 3 \mathrm{HT}<\mathrm{SiNc} 10<\mathrm{N} 2200<$ SiNc6. Considering the surface energy alone, SiNc10 and SiNc6 would be predicted to be located at the P3HT/N2200 interface and at N2200 domains, respectively (details are described in the Supplementary Material). However, this is not the case as mentioned above: both dyes are not likely to be well mixed with N2200. This is probably because N2200 is likely to form aggregates in solid films and hence expels dye molecules from the aggregates.[25-27] The same is true for highly crystalline P3HT domains. These indicate that the majority of SiNc dye molecules are primarily located at the 
P3HT/N2200 interface in ternary blend films. In terms of the surface energy, SiNc10 is considered to be more mixed with P3HT than SiNc6, which is consistent with the absorption change we observed. We therefore conclude that such mixed distribution at the interface is beneficial for the dye sensitization rather than formation of large dye aggregates.

\section{Conclusion}

We fabricated ternary blend solar cells based on P3HT, N2200, and SiNc dye, which have cascaded energy structures both in HOMO and LUMO levels. For comparison, two SiNc dye molecules were employed: one is silicon naphthalocyanine bis(tri-n-hexylsilyl oxide) (SiNc6) and the other is silicon naphthalocyanine bis(n-decyldimethylsilyl oxide) (SiNc10). For SiNc6, the device performance showed a maximum efficiency of $1.2 \%$ at $15 \mathrm{wt} \%$ and then rapidly degraded at higher dye loading. For SiNc10, the power conversion efficiency increased with dye loading concentrations and reached the maximum $(1.4 \%)$ at $30 \mathrm{wt} \%$. This difference is mainly due to the different dye distribution in ternary blend films. On the basis of the absorption spectral analysis, we found that both dyes are likely to be segregated from P3HT and N2200 and hence located at the interface. In terms of the surface energy of 
each material, SiNc10 is considered to be more mixed with P3HT than SiNc6. In other words, SiNc6 would form large aggregates at the interface and hence hinder charge transport, resulting in degraded device performance at higher dye loading concentrations. On the other hand, SiNc10 would be well mixed with P3HT at the interface even at high dye loading concentrations and remain efficient charge generation and charge transport, resulting in the improved device performance at $30 \mathrm{wt} \%$. In conclusion, dye distribution in ternary blends, which have critical impact on the device performance, can be controlled by a careful molecular design. 


\section{Acknowledgments}

This work was partly supported by the FIRST program (Development of Organic

Photovoltaics toward a Low-Carbon Society: Pioneering Next Generation Solar Cell

Technologies and Industries via Multi-manufacturer Cooperation) and the JST PRESTO

program (Photoenergy Conversion Systems and Materials for the Next Generation Solar

Cells). 


\section{References}

(1) Green MA, Emery K, Hishikawa Y, Warta W, Dunlop ED. Prog. Photovolt: Res. Appl. 2014; 22: 1-9.

(2) You J, Dou L, Yoshimura K, Kato T, Ohya K, Moriarty T, Emery K, Chen CC, Li G, Yang Y. Nat. Commun. 2013; 4: 1446.

(3) Bundgaard E, Krebs FC. Sol. Energy Mater. Sol. Cells 2007; 91: 954-985.

(4) Liang Y, Yu L. Acc. Chem. Res. 2010; 43: 1227-1236.

(5) Beaujuge PM, Fréchet JMJ. J. Am. Chem. Soc. 2011; 133: 20009-20029.

(6) Li G, Zhu R, Yang Y. Nat. Photon. 2012; 6: 153-161.

(7) Zhou W, Zhang ZG, Ma L, Li Y, Zhan X. Sol. Energy Mater. Sol. Cells 2013; 112:

$13-19$.

(8) Li YF. Acc. Chem. Res. 2012; 45: 723-733.

(9) Peet J, Tamayo AB, Dang XD, Seo JH, Nguyen TQ. Appl. Phys. Lett. 2008; 93: 163306.

(10) Honda S, Nogami T, Ohkita H, Benten H, Ito S. ACS Appl. Mater. Interfaces 2009;

1: $804-810$.

(11) Honda S, Ohkita H, Benten H, Ito S. Chem. Commun. 2010; 46: 6596-6598.

(12) Honda S, Ohkita H, Benten H, Ito S. Adv. Energy Mater. 2011; 1: 588-598. 
(13) Honda S, Yokoya S, Ohkita H, Benten H, Ito S. J. Phys. Chem. C 2011; 115:

$11306-11317$.

(14) Kubo Y, Watanabe K, Nishiyabu R, Hata R, Murakami A, Shoda T, Ota H. Org. Lett. 2011; 13: 4574-4577.

(15) Ameri T, Min J, Li N, Machui F, Baran D, Forster M, Schottler KJ, Dolfen D,

Scherf U, Brabec CJ. Adv. Energy Mater. 2012; 2: 1198-1202.

(16) Yamamoto S, Kimura M. ACS. Appl. Mater. Interface 2013; 5: 4367-4373.

(17) Xu H, Wada T, Ohkita H, Benten H, Ito S. Electrochim. Acta 2013; 100: 214-219.

(18) Ameri T, Khoram P, Min J, Brabec CJ. Adv. Mater. 2013; 25: 4245-4267.

(19) Chen YC, Hsu CY, Lin RYY, Ho KC, Lin JT. ChemSusChem 2013; 6: 20-35.

(20) Liu F, Gu Y, Shen XB, Ferdous S, Wang HW, Russell TP. Prog. Polym. Sci. 2013;

38: $1990-2052$.

(21) Huang JS, Goh T, Li X, Sfeir MY, Bielinski EA, Tomasulo S, Lee ML, Hazari N, Taylor AD. Nat. Photon. 2013; 7: 479-485.

(22) Ito S, Hirata T, Mori D, Benten H, Lee LT, Ohkita H. J. Photopolym. Sci. Technol. 2013; 26: 175-180.

(23) Kochi M, Harada Y, Hirooka T, Inokuchi H. Bull. Chem. Soc. Jpn. 1970; 43: 26902702. 
(24) Seki K, Kanai K. Mol. Cryst. Liq. Cryst. 2006; 455: 145-181.

(25) Schubert M, Dolfen D, Frisch J, Roland S, Steyrleuthner R, Stiller B, Chen Z,

Scherf U, Koch N, Facchetti A, Neher D. Adv. Energy Mater. 2012; 2: 369-380.

(26) Yan H, Collins BA, Gann E, Wang C, Ade H, McNeill CR. ACS Nano 2012; 6:

$677-688$.

(27) Steyrleuthner R, Schubert M, Howard I, Klaumünzer B, Schilling K, Chen Z,

Saalfrank P, Laquai F, Facchetti A, Neher D. J. Am. Chem. Soc. 2012; 134: 18303-

18317. 


\section{Figure Captions}

Figure 1. Chemical structures and energy diagram of materials employed in this study: P3HT, SiNc6, SiNc10, and N2200 from left to right. The figures represent the HOMO (lower) and LUMO (upper) energy in electron volts.

Figure 2. a), b) $J-V$ characteristics, c), d) EQE spectra, and e), f) photon absorption efficiency of P3HT/N2200/dye blend solar cells: a), c), e) dye = SiNc6 and b), d), f) dye $=\mathrm{SiNc} 10$ at 0 (gray lines), 5 (broken lines), 15 (dashed dotted lines), 30, (dashed double-dotted lines), and $50 \mathrm{wt} \%$ (solid lines). The photon absorption efficiency is estimated from twice the absorbance of the films assuming the reflection at the metal electrode.

Figure 3. Integrated photocurrent of P3HT/N2200/dye ternary solar cells with different dye loading concentrations, which is calculated from the EQE and the solar spectrum integrated a) from 360 to $650 \mathrm{~nm}$ (photocurrent from P3HT), b) from 650 to $750 \mathrm{~nm}$ (photocurrent from N2200), c) from 750 to $850 \mathrm{~nm}$ (photocurrent from dye), and d) from 360 to $850 \mathrm{~nm}$ (total photocurrent $\approx J_{\mathrm{SC}}$ ): SiNc10 (circles) and SiNc6 (triangles). 
Figure 4. Peak wavelength of the dye absorption band plotted against dye loading concentrations in blend films: P3HT/dye (triangles), N2200/dye (inverted triangles), and P3HT/N2200/dye (circles). a) dye $=$ SiNc6 and b) dye $=$ SiNc10. 


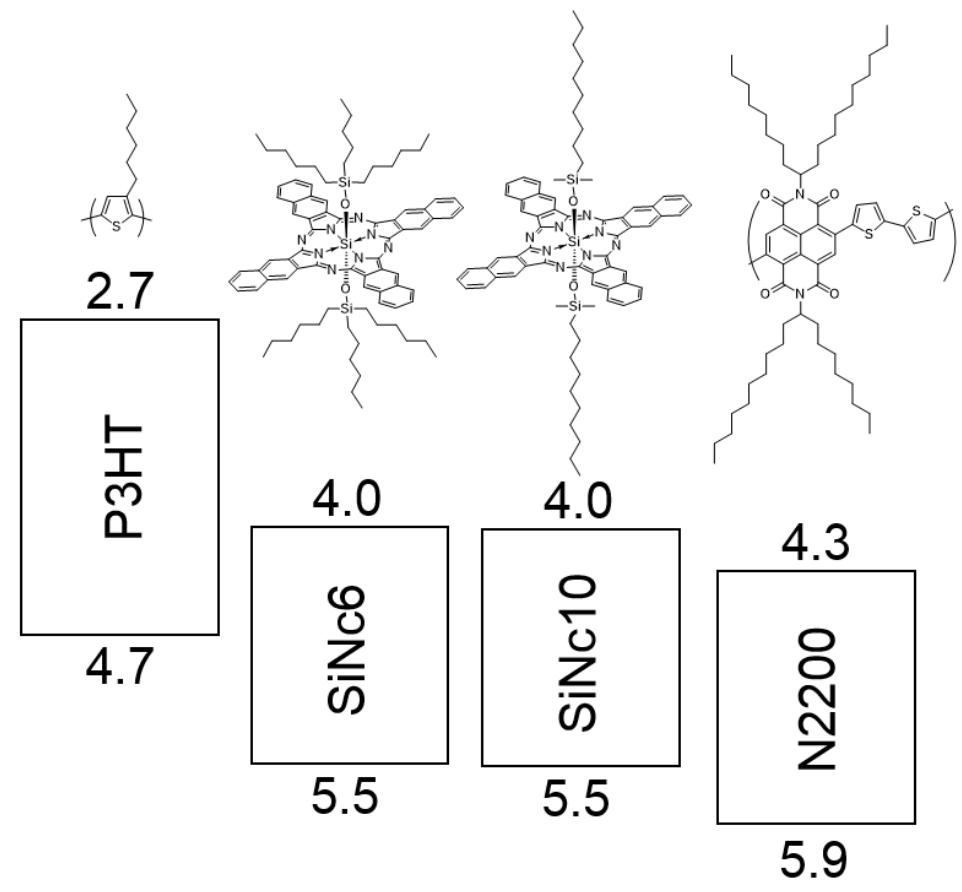

Figure 1 

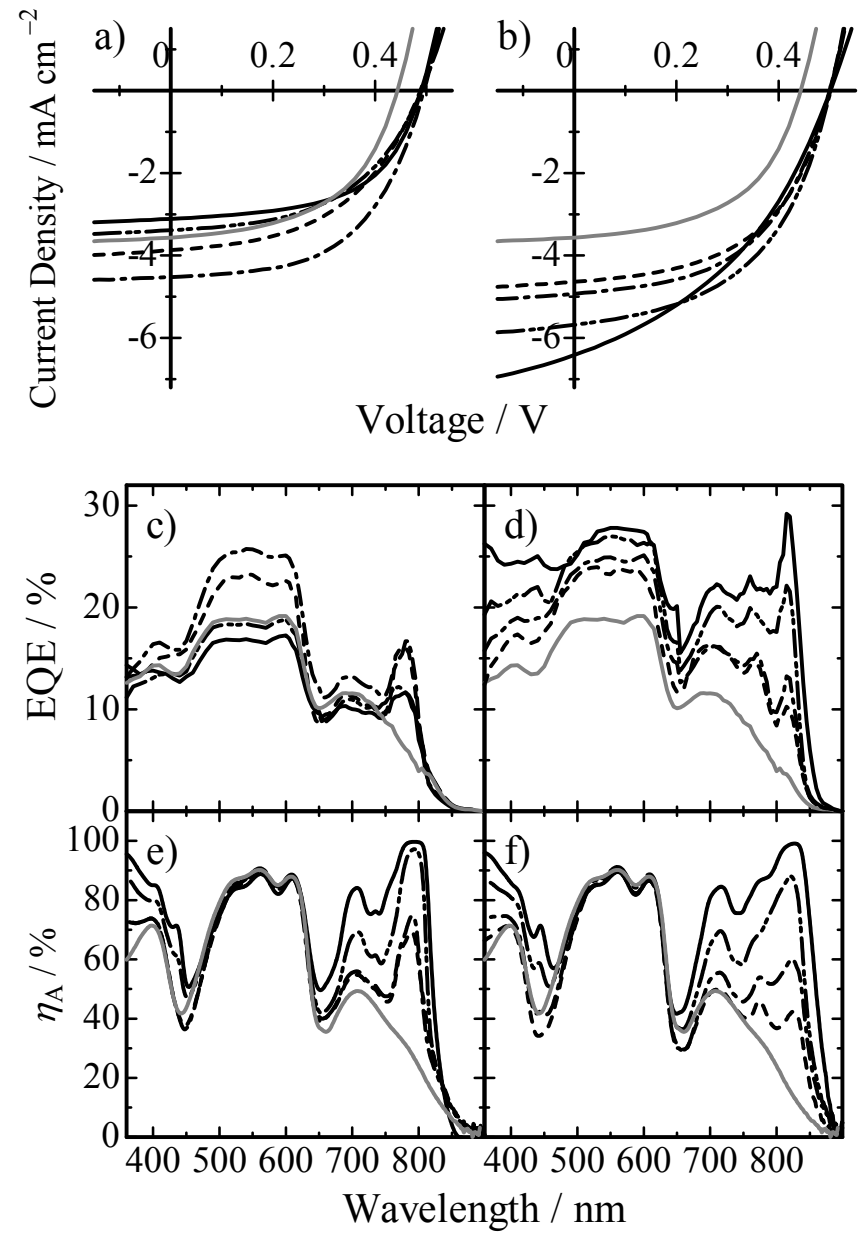

Figure 2 


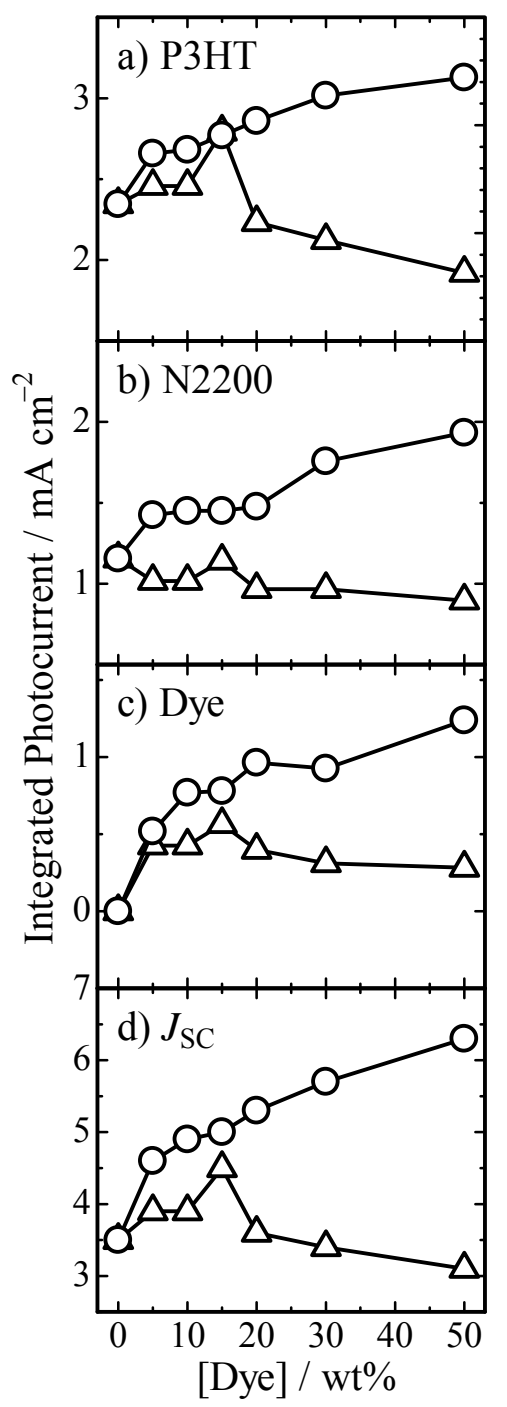

Figure 3 


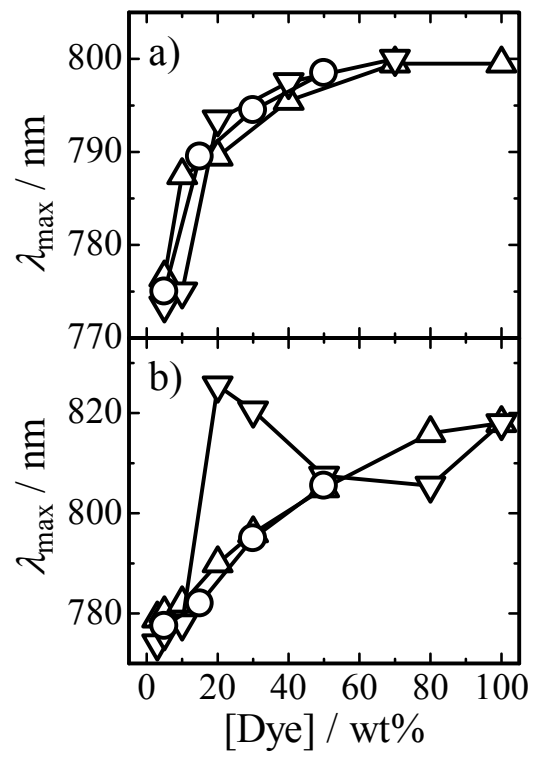

Figure 4 
Table 1. The device parameters of P3HT/N2200/SiNc ternary blend solar cells.

\begin{tabular}{lccccc}
\hline Dye & wt $\%$ & $J_{\mathrm{SC}} / \mathrm{mA} \mathrm{cm}^{-2}$ & $V_{\mathrm{OC}} / \mathrm{V}$ & $\mathrm{FF}$ & $\mathrm{PCE}^{\mathrm{a}} / \%$ \\
\hline & 5 & 4.6 & 0.50 & 0.52 & $1.2 \pm 0.05$ \\
& 10 & 4.9 & 0.50 & 0.49 & $1.2 \pm 0.09$ \\
SiNc10 & 15 & 5.0 & 0.50 & 0.50 & $1.2 \pm 0.1$ \\
& 20 & 5.4 & 0.50 & 0.48 & $1.3 \pm 0.07$ \\
& 30 & 5.7 & 0.50 & 0.50 & $1.4 \pm 0.09$ \\
& 50 & 6.3 & 0.51 & 0.39 & $1.3 \pm 0.04$ \\
\hline & 5 & 3.9 & 0.48 & 0.50 & $0.9 \pm 0.1$ \\
& 10 & 3.7 & 0.48 & 0.52 & $0.9 \pm 0.06$ \\
SiNc6 & 15 & 4.5 & 0.50 & 0.54 & $1.2 \pm 0.09$ \\
& 20 & 3.6 & 0.49 & 0.53 & $0.94 \pm 0.08$ \\
& 30 & 3.4 & 0.49 & 0.50 & $0.84 \pm 0.08$ \\
& 50 & 3.1 & 0.48 & 0.58 & $0.86 \pm 0.03$ \\
\hline No & 0 & 3.8 & 0.45 & 0.48 & $0.81 \pm 0.07$ \\
\hline
\end{tabular}

a) The PCE values are listed with their associated standard deviations.

Table 2. The surface energy of each material employed in this study.

\begin{tabular}{ll}
\hline Materials & Surface Energy $/ \mathrm{mJ} \mathrm{m}^{-2}$ \\
\hline P3HT & 18.4 \\
$\mathrm{~N} 2200$ & 21.9 \\
SiNc6 & 23.0 \\
SiNc10 & 21.3 \\
\hline
\end{tabular}




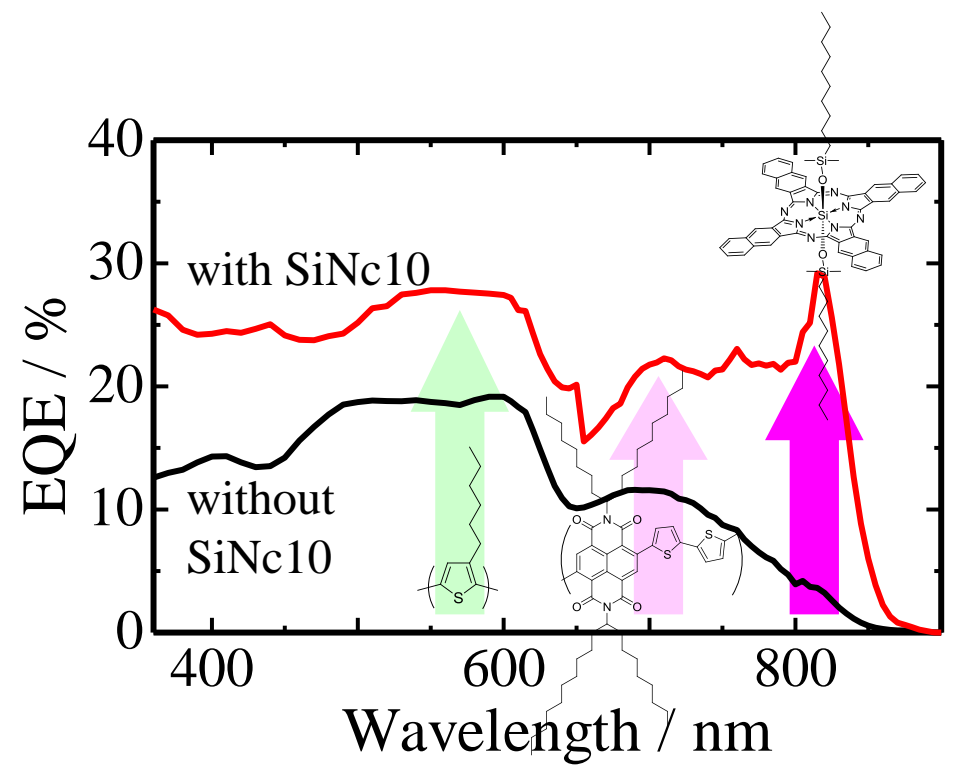

